\title{
A study on awareness about temporary contraceptive methods among women in reproductive age group
}

\author{
Sharan Kumar Karthikeyan', Kohila Kalimuthu ${ }^{2 *}$
}

\author{
${ }^{1}$ MBBS Student, Saveetha Medical College Hospital, Chennai, Tamil Nadu, India \\ ${ }^{2}$ Department of Obstetrics and Gynecology, Saveetha Medical College Hospital, Chennai, Tamil Nadu, India
}

Received: 04 September 2019

Accepted: 04 October 2019

\author{
*Correspondence: \\ Dr. Kohila Kalimuthu, \\ E-mail: kohilakalimuthu@gmail.com
}

Copyright: () the author(s), publisher and licensee Medip Academy. This is an open-access article distributed under the terms of the Creative Commons Attribution Non-Commercial License, which permits unrestricted non-commercial use, distribution, and reproduction in any medium, provided the original work is properly cited.

\begin{abstract}
Background: This study focuses on the awareness about temporary contraceptive methods among women in reproductive age group (15-45 years). The temporary contraceptive methods are barrier method, hormonal methods and intrauterine method. The need to study the awareness of temporary contraceptive among women is important to avoid Abortion, MTP and to reduce maternal mortality. The purpose of this study is to assess the awareness of temporary contraceptive methods among women within the reproductive age group of 15 to 45 years in the community. Explore women's understanding, interpretations of contraceptives. Suggestions to improve Birth control and enhance maternal, child health programmes.

Methods: Cross-sectional descriptive study (samples were drawn from relevant population and studied once) conducted among the outpatients visiting the obstetrics and gynaecology department of Saveetha Medical College and Hospital. The study was conducted from $15^{\text {th }}$ April 2019 to $14^{\text {th }}$ July 2019 using pretested questionnaire by interview method.

Results: The study shows $72 \%$ of women were aware of condoms and $92 \%$ of women were aware about sterilization method. $38 \%$ of the women who participated in the study belonged to the age group (36-45) and maximum usage of temporary contraceptives was found among this age group. We observe $56 \%$ of the women were aware that these contraceptives can be obtained at the government hospitals and $7 \%$ of the women were not aware where to get these services. $48 \%$ of the women got information about contraceptives from health personnel.

Conclusions: The success of family planning programs can only be achieved by increasing the awareness of various contraceptives available. It is necessary that supplies of contraceptives are accessible, available and affordable to the general public with ease. Awareness can be improved by expanding health care facilities to peripheral areas.
\end{abstract}

Keywords: Awareness, Family planning, Health care, Knowledge, Reproductive women, Temporary contraception

\section{INTRODUCTION}

India was the first country in the world to launch a family planning programme in 1952, with the objective of "reducing birth rate and to stabilise the population". Gradually, the focus of the programme moved away from population control to population stabilization, and then was integrated with the maternal and child health programme. Family planning became an important tool to reduce maternal and child mortality. ${ }^{1}$ Family planning is defined as a conscious decision by individuals or couples to choose for themselves when to start having children, how many children to have, how to space them or when to stop having children.

In 2015, India reported 15.6 million of abortions at the rate of 47.0 abortions per 1000 women aged between 15- 
49 years which is one third of total pregnancies. The high rate of abortion follows a high number of unintended pregnancies. The rate of unintended pregnancies was 70.1 per 1000 women aged 15-49 years almost half the pregnancy that were reported during that period. ${ }^{2}$

A woman's ability to choose when to become pregnant has a direct impact on her health and well-being. Closely spaced and ill-timed pregnancies /child births contribute to some of the world's highest infant mortality rates. Both mother and Infant also have a greater risk of death and poor health.

This study focuses on the awareness about temporary contraceptive methods among women in reproductive age group (15-45 years). The temporary contraceptive methods may be broadly classified as below:

\section{Barrier methods}

These methods prevent sperm from entering the uterus. Barrier methods are removable, easy to use and have few side effects. It includes

- $\quad$ Condoms (both male and female)

- Diaphragm and Cervical cap

- Contraceptive sponge.

\section{Hormonal methods}

Hormonal methods cause changes in the woman's reproductive cycle and include birth control pills, birth control patches, emergency contraception pill, Implants and so on. Unlike barrier methods, hormonal methods do not interfere with sex.

\section{Intrauterine methods}

An intrauterine device or IUD is put in the woman's uterus. There are two types of IUD. The copper IUD or an IUD with hormones implanted on it.

The United Nations has estimated that the world population grew at an annual rate of 1.23 percent during 2000-2010. With a definite slowing down of population growth in china, it is now estimated that by 2030, India will most likely overtake china to become the most populous country on the earth with 17.9 percent population living here. ${ }^{3}$ According to 2011 census, total population in Tamil Nadu is 7, 21, 47, 030 with a growth rate of $15.6 \%(2001-2011)$

Despite the increase in usage of contraceptive devices there still exists a deficit in the awareness of contraceptive use within the community. ${ }^{4}$

The need to study the awareness of temporary contraceptive among women is important to avoid Abortion, MTP and to reduce maternal mortality. Through this study Individuals have also acquired knowledge about temporary contraceptive methods and places from where they can get the hormonal pill, condoms or IUCD. Any misconception regarding contraceptive methods was cleared.

The purpose of this study is to:

- Assess the awareness of temporary contraceptive methods among women within the reproductive age group of 15 to 45 years in the community

- Explore women's understanding and interpretations of contraceptives

- Suggestions to improve birth control and enhance maternal, child health programmes.

\section{METHODS}

Study design: cross-sectional descriptive study (samples were drawn from relevant population and studied once).

Study area: Saveetha Medical College and Hospital.

Study population: Women within the reproductive age group (15-45 years) coming to Outpatient department of Obstetrics and Gynaecology, Saveetha Medical Hospital

Study unit: Female individuals within the reproductive age group (15-45 years).

\section{Inclusion criteria}

- Outpatient women coming to Saveetha Medical Hospital

- Women belonging to age (15-45 years)

- Women willing to participate.

\section{Exclusion criteria}

- Women with mental disorders

- Participants not willing to respond even after requesting and ensuring confidentiality.

Duration of the Study was from March 2019 to May 2019. Sample size was 100 outpatients and sampling technique was convenience sampling.

Data collected with pre-tested questionnaire by interview method.

\section{Procedure}

Ethical clearance: the process of acquiring relevant data for the study began after its approval by the IRB, SMCH.

Informed consent from participants: Female patients within the reproductive age group of 15-45 years who had given informed consent to participate in this study constitute sample for this study. 


\section{Interview method}

using pretested questionnaire was the method used in acquisition of relevant data.

Questionnaire: which was validated by the Obstetrics and Gynaecology Department has 14 questions to assess the awareness of the patient. After providing information sheet and acquiring the informed consent, questions were asked and answers were recorded on paper.

\section{Statistical analysis}

The data collected was entered, organized and quantified in excel spreadsheet.

\section{RESULTS}

\section{Socio-demographic details}

The socio-demographic details of 100 women participants who took part in the study are as follows:

\section{Age distribution}

The samples were classified under 3 age group and studied.

Table 1: The distribution of the sample based on age.

\begin{tabular}{|lll|}
\hline Age (in years) & Frequency (No.) & Percentage (\%) \\
\hline $15-25$ & 29 & 29 \\
\hline $26-35$ & 33 & 33 \\
\hline $36-45$ & 38 & 38 \\
\hline Total & $\mathbf{1 0 0}$ & $\mathbf{1 0 0}$ \\
\hline
\end{tabular}

Thus, we understand that $38 \%$ of the women who participated in the study belonged to the age group (3645).

\section{Educational qualification}

The educational qualification of the women was assessed and classified under primary education, secondary education, high school, graduate and others.

Table 2: Sample classified based on their education.

\begin{tabular}{|lll|}
\hline Education level & Frequency (No Percentage (\%) \\
\hline Primary education & 9 & 9 \\
\hline Secondary education & 41 & 41 \\
\hline High school & 23 & 23 \\
\hline Graduate and above & 25 & 25 \\
\hline No formal education & 2 & 2 \\
\hline Total & $\mathbf{1 0 0}$ & $\mathbf{1 0 0}$ \\
\hline
\end{tabular}

Thus, we understand that $98 \%$ of the women in the sample were literate. $41 \%$ of the women had secondary level education.

\section{Occupational status}

The occupational status of the women was enquired. The various occupational levels were professional, skilled worker, unemployed and others. The occupational status of the women is as depicted in Figure 1 below.

Thus, it is clear that $63 \%$ of the women in the community were unemployed and $13 \%$ of the women had occupation of professional level.

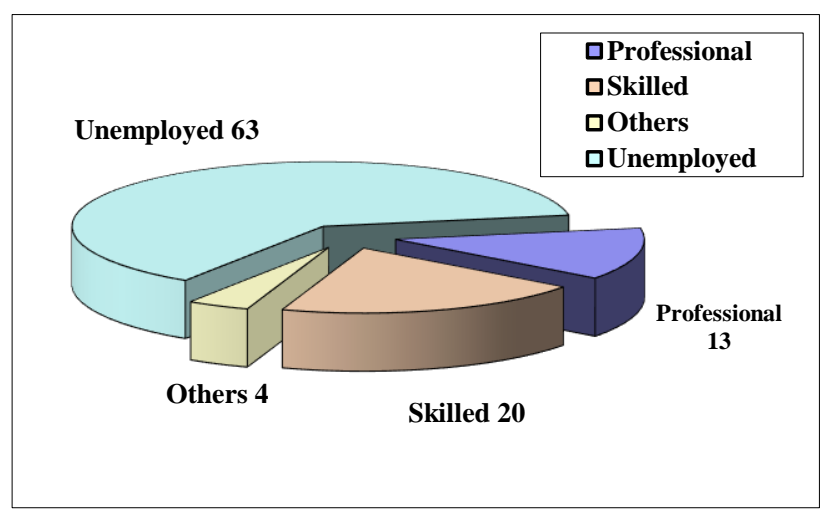

Figure 1: Occupational status.

\section{Religion}

The religious practice of the women was enquired and the various religion being Hindu, Christian, Muslim and others.

Table 3: Sample classified based on their religion.

\begin{tabular}{|lll|}
\hline Religion & Frequency (No.) & Percentage (\%) \\
\hline Hindu & 89 & 89 \\
\hline Christian & 9 & 8 \\
\hline Muslim & 2 & 2 \\
\hline Others & 0 & 0 \\
\hline Total & $\mathbf{1 0 0}$ & $\mathbf{1 0 0}$ \\
\hline
\end{tabular}

Thus, it is understood that the majority of respondents were Hindus and only 2 percent were Muslims.

\section{Marital status}

The women were asked about their marital status. They were either married or not married.

Table 4: Samples according to their marital status.

\begin{tabular}{|lll|}
\hline Marital status & Frequency (No.) & Percentage (\%) \\
\hline Married & 86 & 86 \\
\hline Unmarried & 14 & 14 \\
\hline Total & $\mathbf{1 0 0}$ & $\mathbf{1 0 0}$ \\
\hline
\end{tabular}

Thus, it is clear that most of the women $(86 \%)$ were married in the sample under study. 


\section{Knowledge of contraceptives and various contraceptive methods}

The awareness regarding contraception and various contraceptive methods like condom, IUCD, Injectables, Hormonal pills, and emergency contraception, were assessed. The data was classified as depicted in the Figure 2 below.

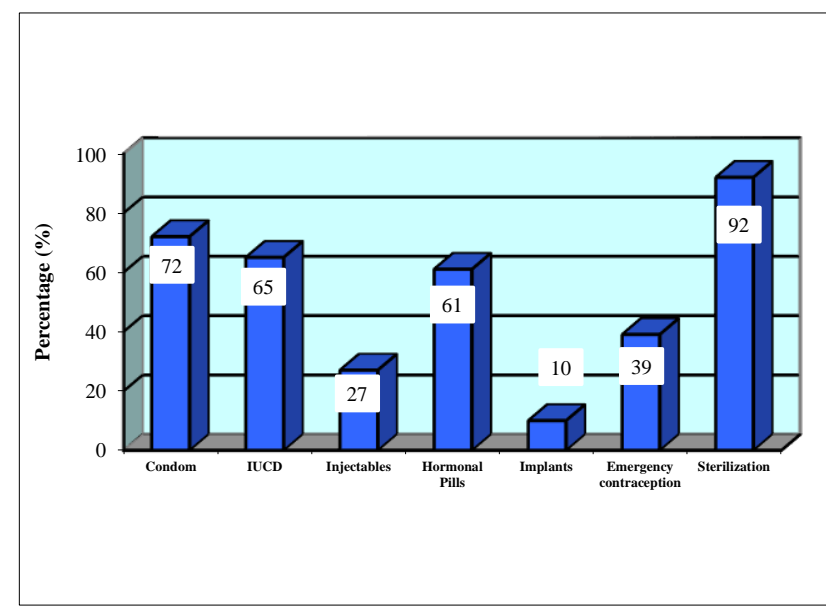

Figure 2: Awareness of various contraceptives by women.

From the above table it is clear that $72 \%$ of the women were aware of condoms and only $39 \%$ of women were aware of emergency contraception. In this study, $92 \%$ of women were aware about sterilization method and the source of information was health personnel.

\section{Knowledge regarding procurement of temporary contraceptive devices}

The women were assessed regarding their knowledge on procurement of temporary contraceptive devices. The sources being Government hospitals, Health centers, Private health institutions, Medical shop and pharmacy. The responses are depicted in the Figure 3 below.

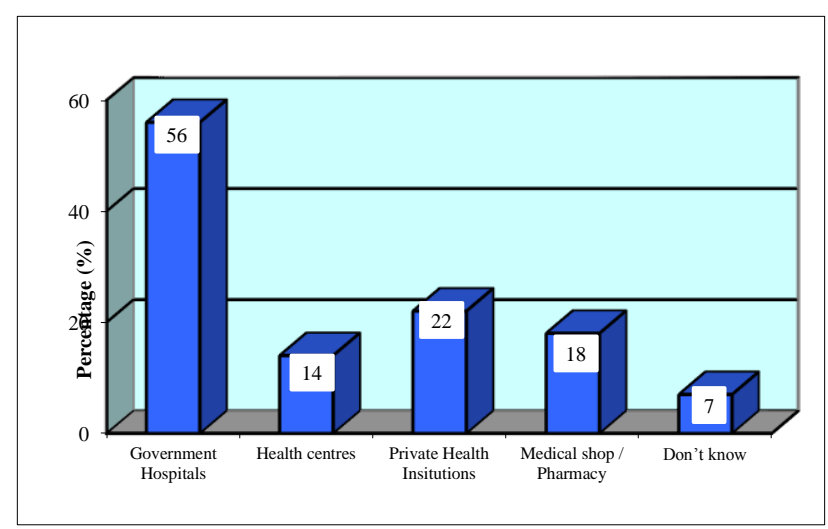

Figure 3: Knowledge among women regarding contraceptive procurement.
The total will not equal to 100 as the same sample had multiple answers.

We observe $7 \%$ of the women are not aware as to where to get these services and 56\% of the women are aware that these can be obtained at the government hospitals.

\section{Source of information}

The source of information of the women was assessed and their sources being media, husband, family and health personnel.

Table 5: Source of information about temporary contraceptive.

\begin{tabular}{|lll|}
\hline Source of information & $\begin{array}{l}\text { Frequency } \\
(\text { No. })\end{array}$ & $\begin{array}{l}\text { Percentage } \\
(\%)\end{array}$ \\
\hline Media & 18 & 18 \\
\hline Husband & 16 & 16 \\
\hline Family / friends & 14 & 14 \\
\hline Health personnel & 48 & 48 \\
\hline Others & 22 & 22 \\
\hline
\end{tabular}

The total will not be equal to 100 as the sample can have multiple answers.

Thus, we understand that most of the women, $48 \%$ of the women got their information from health personnel.

\section{DISCUSSION}

This is a cross sectional study that was conducted to assess the awareness of temporary contraceptive methods among women within the reproductive age group of 15 to 45 years in the community. The results obtained from the study show that

- $100 \%$ of the women were familiar with one or more contraceptive method. This is similar to the study conducted by International Journal of Science and Research. $^{5}$

- More than $50 \%$ of the sample saw government hospitals as a source for procurement of contraceptives followed by private health institution, medical shop and health centre. ${ }^{6}$

- Knowledge about sterilization is higher $92 \%$ and it is low for spacing methods This is similar to the study conducted by National Family Health survey. ${ }^{7}$

- Among spacing methods, awareness about condoms was higher $(72 \%)$, the results are similar to the study conducted at National Medical college, Karachi, and DLHS $3 .^{7}$

- $\quad 7 \%$ of the women did not know the place to acquire them. This resonates with the result obtained from a study conducted in the slums of Mumbai that found $14 \%$ of its sample oblivious to this piece of knowledge. ${ }^{8}$ 
- Nearly $50 \%$ of women acquired information on contraception from health personnel. This is in congruence with the results obtained from studies conducted in Udipi, Karnataka, slums in Mumbai and Shillong, Meghalaya where health workers had served as the source of information for the women. ${ }^{8-}$ 10

\section{CONCLUSION}

\section{The results from this study shows that}

- $100 \%$ of the sample population is aware of at least one method of contraception

- More than $60 \%$ of women were aware about atleast one of the temporary contraceptives, Condom (72\%), IUCD (65\%) and hormonal pills (61\%)

- Less than $40 \%$ women were aware about emergency contraception pill

- $7 \%$ of the women did not know where to procure contraceptives

- Health personnel were the source of information about contraceptives for nearly half of the women $(48 \%)$.

The success of family planning programs can only be achieved by increasing the awareness of various contraceptives available. It is important for contraceptive information providers to have sound knowledge of various methods of contraception and their proper usage to remove fears about contraception.

The difficulty to access the contraceptive provider limits the usage of contraceptives. Hence, it is necessary that supplies of contraceptives are accessible, available and affordable to the general public with ease.

To improve awareness, PHC's may expand their coverage / health care facilities to peripheral areas. The government may also utilize the media to increase the awareness of contraceptive to adopt proper family planning methods.

Funding: No funding sources Conflict of interest: None declared

Ethical approval: The study was approved by the Institutional Ethics Committee

\section{REFERENCES}

1. Rahman S, Nessa F. Neo-natal mortality patterns in rural Bangladesh. J Trop Pediatr. 1989;35(4):199202.
2. Singh S, Shekhar C, Acharya R, Moore AM, Stillman M, Pradhan MR, et al. The incidence of abortion and unintended pregnancy in India, 2015. The Lancet Global Health. 2018;6(1):e111-20.

3. Census of India. Size, Growth Rate and Distribution of Population, 2011. Available at: http://censusindia.gov.in/2011-prov-results/data files/india/Final_PPT_2011_chapter3.pdf. Accessed on $24^{\text {th }}$ January 2015.

4. Prachi R, Das GS, Ankur B, Shipra J, Binita K. A study of knowledge, attitude and practice of family planning among the women of reproductive age group in Sikkim. Religion. 2008;35(44years):34.

5. Anjum S, Durgawale PM, Shinde M. Knowledge of contraceptives methods and appraisal of health education among married woman. Int $\mathbf{J}$ Sci Res. 2014;3(3):584-90.

6. Nair RV, Ashok VG, Solanke PV. A study on contraceptive use among married women of reproductive age group in a rural area of Tamilnadu, India. Int J Reprod Contracept Obstet Gynecol. 2016;5(9):3147-52.

7. Khan A, Hashmi HA, Naqvi Z. Awareness and practice of contraception among child bearing age women, conducted at Liaquat national medical college and hospital Karachi. J Surg Pak. 2011;16(4):179-82.

8. Makade KG, Padhyegurjar M, Padhyegurjar SB, Kulkarni RN. Study of contraceptive use among married women in a slum in Mumbai. Nat J Comm Med. 2012;3(1):40-3.

9. Sherpa SZ, Sheilini M, Nayak A. Knowledge, attitude, practice and preferences of contraceptive methods in Udupi district, Karnataka. J Family Repro Health. 2013;7(3):115.

10. Pegu B, Gaur BP, Sharma N, Singh A. Knowledge, attitude and practices of contraception among married women. Int $\mathbf{J}$ Reprod Contracept Obstet Gynecol. 2017;3(2):385-8.

Cite this article as: Karthikeyan SK, Kalimuthu K. A study on awareness about temporary contraceptive methods among women in reproductive age group. Int J Reprod Contracept Obstet Gynecol 2019;8:4414-8. 